\title{
Estudo histórico sobre a formação profissional na Escola de Educação Física e Esporte da Universidade de São Paulo (1980-1990)
}

\author{
Edivaldo Góis Junior ${ }^{1}$ \\ Vilma Leni Nista-Piccolo ${ }^{2}$ \\ Bruna Ribeiro Dias ${ }^{3}$ \\ Sammia Smirna Freitas Teixeira ${ }^{3}$ \\ Vaneska Carmona Tapia de Freita ${ }^{3}$ \\ Camila Queiroz de Souza ${ }^{3}$ \\ ${ }^{1}$ Faculdade de Educação, Universidade Federal do Rio de Janeiro, Rio de Janeiro, RJ, Brasil \\ 2 Programa de Pós-Graduação em Educação Física, \\ Universidade Federal do Triângulo Mineiro, Uberaba, MG, Brasil \\ ${ }^{3}$ Grupo de Estudos Culturais em Educação Física, \\ Universidade Cidade de São Paulo, São Paulo, SP, Brasil
}

\begin{abstract}
Resumo: Este estudo tem como objetivo analisar as influências dos debates sobre educação física dos anos 1980 no âmbito da Escola de Educação Física e Esporte (EEFE-USP); em específico, interessa analisar o contexto histórico das reformas curriculares dos anos 1990 nesta instituição. Na coleta e análise dos dados empíricos adotou-se uma abordagem qualitativa através de uma pesquisa histórica, utilizando-se do método de história oral apresentado por Paul Thompson (2002). O estudo revela a existência de divergências internas, as quais, após análise interpretativa, são percebidas como ainda presentes na USP. Percebe-se que os informantes têm visões diferentes sobre a formação profissional da escola, bem como conceitos divergentes sobre educação física e esporte.
\end{abstract}

Palavras-chave: educação física; história oral; formação de recursos humanos.

An historical approach to the professional training of the School of Physical Education an Sport at University of São Paulo during the 1980's and 1990's

Abstract: This study aims to examine the influences of debates that occurred during the 1980's in the physical education area at the School of Physical Education an Sport at University of São Paulo (EEFEUSP). In particular, we are interested in the historical context of the curricula reforms of the 1990's in that institution. To apply an historical perspective, we used a qualitative method of the oral history approach by Paul Thompson (2002). After the interpretive analysis, we perceived current intrinsic differences with respect to the study's subject at that university. Participants have different views about professional training, as well as divergent concepts about physical education and sport.

Keywords: physical education; oral history; human resources training.

\section{Introdução}

Há mais de duas décadas que constantes reflexões têm sido promovidas por pesquisadores e seus debates acerca da formação profissional em educação física no Brasil. Estudos publicados sobre essa área de intervenção têm demonstrado diferentes apontamentos, conforme mostram os trabalhos de Barros (1996), Betti e Betti (1996), Carmo (1987), Oliveira e Da Costa (1999), Darido e Rangel (2005), Kunz (1999), Freire, Verenguer e Reis (2002), Galvão (2002), Pérez Gallardo (1997), Kolyniak Filho (1998), Taffarel (1998), Manoel e Tani (1999), Oliveira (2000), Silva e outros (1991) e Tojal (1989). Alguns autores declaram maior preocupação com as estruturas necessárias aos saberes docentes na área da educação física, enquanto outros enfatizam que ainda há certo desconhecimento sobre quais são as maiores necessidades na formação do professor (NISTA-PICCOLO, 2010).

Até 1987 os cursos de licenciatura se destinavam a formar o professor de educação física independentemente do ambiente em que ele fosse atuar. A partir da Resolução CFE no 03/87, a formação ficou diferenciada em bacharéis e licenciados, devido à expansão da área. Dessa maneira, começaram a ser exigidas especificidades no currículo do ensino superior. Em 2002, o estabelecimento de Diretrizes Curriculares Nacionais para a formação de educadores nos cursos de nível superior afetou a formação profissional em educação física. 
Recomendava-se que as peculiaridades regionais fossem contempladas nos currículos dos cursos em diferentes recantos do país, eliminando-se a exigência de um currículo mínimo obrigatório, e passando-se a trabalhar com a proposta de matriz curricular. Não se sabe, até o momento, o resultado destas resoluções e diretrizes mais recentes (1987 e 2002) sobre a elaboração e implantação curricular na formação profissional em educação física no Brasil (NISTA-PICCOLO, 2010).

\begin{tabular}{|c|}
\hline $\begin{array}{l}\text { Diante dessas constatações, torna-se } \\
\text { pportante analisar as influências dessas } \\
\text { formas, assim como identificar os debates } \\
\text { corridos a respeito dessas mudanças. Por se } \\
\text { na das mais importantes instituições de ensinc } \\
\text { essa área de conhecimento, este estudo se } \\
\text { opõe a analisar esses aspectos vivenciados na } \\
\text { stória da Escola de Educação Física e Esporte } \\
\text { Universidade de São Paulo (EEFE-USP) }\end{array}$ \\
\hline
\end{tabular}

Nos anos 1980, com o fim da ditadura militar, uma nova geração de professores de educação física criticou as bases da educação física dos anos 1960 e 1970, influenciada pelo esporte de alto rendimento (MAGALHÃES, 2005). Uma crítica de natureza mais política se exacerbou no sentido do esporte como alienador (SOARES, 1996). As promessas de uma potência esportiva brasileira não se concretizaram. O modelo piramidal não fez do Brasil uma potência esportiva, embora os meios de comunicação e alguns políticos ainda se refiram à educação física escolar como celeiro de atletas. No meio acadêmico da área, essa visão foi e é duramente criticada. $\mathrm{Na}$ verdade, esse paradigma ainda persiste no campo da formação profissional da área, pois há pouco trabalho estruturado sobre isso em termos científicos e acadêmicos. Desse modo, como afirmam Darido e Rangel (2005), existe hoje na educação física um confronto entre uma formação profissional técnica e uma formação científica. Um confronto que se iniciou na década de 1980. Betti e Betti (1996) relatam que essa década sustentou dois modelos de currículo para a formação profissional que se consolidaram ao longo dos anos 1990: o currículo tradicional-esportivo e o currículo técnicocientífico.
Betti e Betti (1996) descrevem que o currículo técnico-científico surge no Brasil nos anos 1980, acompanhando os debates epistemológicos da área. Seus defensores analisavam a educação física como uma área de conhecimento, ou uma ciência focada no estudo do movimento humano. Com isso, relatam Betti e Betti (1996), as disciplinas teóricas tiveram sua carga horária aumentada no currículo. No entanto, a dicotomia entre teoria e prática foi reforçada ao longo dos anos 1990. Vianna e Lovisolo (2009) confirmam o mesmo contexto para os anos 1980, contudo apontam para outro viés, com um forte apelo contrário ao chamado tecnicismo na educação física. Com isso, os aspectos técnicos e o desenvolvimento de habilidades deixaram de ser o foco da educação física nesses anos.

Este texto pretende desvelar algumas nuances dos debates ocorridos nessa época na EEFEUSP, os quais ainda não se dissiparam, mostrando-se muito presentes nos discursos dos integrantes da educação física. A descrição desse contexto aponta para a formação de grupos antagônicos na educação superior da educação física, sendo um deles marcado pela tradição esportiva e o outro pela orientação técnicocientífica. Entretanto, não é possível considerar os defensores da formação científica como um bloco unívoco, pois havia desde os anos 1980 inúmeras divergências e tensões internas. Assim, buscamos descrever esse contexto no universo da EEFE-USP.

\section{A escola de Educação Física da USP}

Para organizar essa trama, apontamos inicialmente para os entendimentos sobre educação física expressos por Tani et al. 1988 e Tani, 2007, um dos principais personagens da EEFE da USP (Escola de Educação Física e Esporte da Universidade de São Paulo) nos anos 1980. Tomamos como referência para esse olhar os escritos de Daólio (1998; 2005), um dos estudiosos de personalidades da área na década de 1980.

Go Tani tornou-se professor da USP em 1982. Em 1988, em conjunto com outros autores, publicou o livro Educação Física Escolar: fundamentos de uma abordagem desenvolvimentista, uma referência que se tornou clássica nos anos 1980.

Após essa publicação os autores receberam o rótulo de desenvolvimentista, face à abordagem 
desenvolvida em seus estudos sobre a educação física escolar, segundo a qual a disciplina teria como objetivo a aprendizagem do movimento humano. Defendia-se uma especificidade das aulas de educação física, cuja intenção seria ensinar aos alunos diferentes maneiras de desenvolverem suas habilidades motoras. Era uma abordagem que criticava o tecnicismo por não organizar os conteúdos da educação física escolar por faixa etária, tendo como referência taxonomias do crescimento e desenvolvimento da criança.

Tani et al. (1988) defenderam a aprendizagem do movimento partindo do desenvolvimento das habilidades motoras básicas nas séries iniciais, como rolar, quicar, rebater, chutar, saltar, para posteriormente se concentrarem no ensino de habilidades motoras específicas, como, por exemplo, o saque do voleibol. Em entrevista a Jocimar Daólio, um dos autores, Go Tani disse que o desenvolvimentismo não ensina o voleibol, mas a maneira como se adquirem as habilidades para jogar o voleibol, até mesmo nas horas de lazer (DAÓLIO, 1998).

Além disso, Tani et al. (1988) foram considerados reducionistas por diversos autores (DARIDO; RANGEL, 2005; OLIVEIRA, 1994; DAÓLIO, 2005) à medida que sua proposta ancorava-se em uma perspectiva motora e biológica da educação física, desconsiderando as perspectivas humanas e culturais. Tani (2008) rechaçou essa crítica argumentando que sua proposta nasce de uma teoria sistêmica, que se caracteriza justamente por uma visão ampla de relação entre o todo e as partes, de não dicotomia entre biológico e cultural.

Sobre os anos 1980, Tani (2007) revelou descontentamentos quando aponta que pesquisadores foram perseguidos pelo Colégio Brasileiro de Ciências do Esporte e rotulados de positivistas, reducionistas, neutros, neoliberais, alienados.

Go Tani tornou-se um dos principais articuladores das transformações da EEFE-USP, que, influenciada pelos debates construídos principalmente nos anos 1980 e pela crescente produção científica que ali se desenvolvia, produziu mudanças significativas em sua estrutura pedagógica, administrativa, e, por conseguinte, em sua grade curricular. Nesse momento do texto, destacamos uma articulação entre a personagem histórica e a construção de redes de interdependência que possibilitaram essas transformações. Um dos aspectos mais importantes ressaltado por vários pesquisadores como propulsor dessas transformações foi a criação do curso de Pós-Graduação em Educação Física na USP.

Em 1977, segundo Silva Neto (2002), foi criado o primeiro curso de mestrado em educação física no Brasil. A demanda acadêmica do curso possibilitou a discussão de práticas tradicionais na escola, sobretudo as exigências das aulas práticas. Para ser aprovado na disciplina de atletismo, por exemplo, era necessário correr 10 $\mathrm{km}$; na disciplina de esportes aquáticos, o discente era obrigado a permanecer uma hora em piscina funda, sem contar com nenhum auxílio para se sustentar no meio líquido (SILVA NETO, 2002).

Segundo Silveira e Tani (2008), com a chegada de professores como José Guilmar Mariz de Oliveira, Valdir José Barbanti, Carlos Eduardo Negrão, Go Tani e Alberto Carlos Amadio, todos provenientes de programas de pós-graduação no exterior, a produção científica se intensificou. E, com ela, o número de eventos científicos na área, como congressos e seminários.

Como já expressado neste texto, as discussões dos anos 1980 produziram críticas aos modelos tradicionais. Era o cenário propício às reformas da grade curricular. Em 1979, a duração do curso na EEFE-USP aumentou de três para quatro anos, acompanhada de redução de carga horária das disciplinas ginásticas e esportivas, já anunciando as profundas reformas das décadas seguintes.

Em 1986, o prof. José Guilmar Mariz de Oliveira apresentou uma proposta ao seu departamento na EEFE da USP, que diferenciava a preparação do profissional de educação física de acordo com suas funções. Nessa proposta o professor criticava a formação eclética que se voltava para a atuação em escolas, impedindo a formação de profissionais para a área não escolar. Ressaltava ainda a necessidade de se pensar em preparações diferenciadas para as áreas de educação física e esporte, justificando uma possível proposta de mudança do nome da própria escola (TOJAL, 1994).

Em 1991, segundo Silveira e Tani (2008), foi criado o curso de bacharel em educação física na EEFE-USP. Apoiados pela Resolução $n^{\circ} 3$ de 1987 do Conselho Federal de Educação, os professores da EEFE-USP modificavam o perfil 
do egresso. O perfil tecnicista era abandonado em favor de uma formação teórica mais sólida, além da necessidade de atendimento de novas demandas, como o crescimento das academias de ginástica, da área do lazer, da dança, do esporte, fora do âmbito da educação básica. Segundo Verenguer (1996, p. 71), "uma das justificativas para a reforma era a diferenciação entre os fenômenos da educação física, do esporte, da dança, e da recreação". Sendo assim, como áreas diferentes, exigiam formações diferenciadas. O modelo proposto pela Resolução CFE no $03 / 87$ que criou o bacharelado, abriu caminho para essas reestruturações como, por exemplo, a que aconteceu no curso da Faculdade de Educação Física da Unicamp, que foi criada em 1985 apresentando um currículo mais "pedagogicista" em relação às propostas dos demais cursos (TOJAL, 1994). No início dos anos de 1990 na Unicamp, se estrutura uma nova matriz curricular com mudanças na formação, implantando o bacharelado em técnico desportivo e, posteriormente, em recreação e lazer. O curso da Unesp, da cidade de Rio Claro, também criou nessa época duas habilitações diferenciadas: a licenciatura e o bacharelado (BARROS, 1995).

Contudo, a USP foi além, com o intuito de caracterizar a formação em educação física, criando o curso de bacharel em esporte em 1992 (SILVA NETO, 2002; VERENGUER, 1996). Esse fato tornou-se um dos mais polêmicos nas discussões sobre formação profissional na área. Historicamente relacionados, esporte e educação física foram separados na formação da EEFEUSP.

É exatamente nessa trama que se concentra nosso problema de estudo: como diferentes docentes da EEFE-USP, de diferentes formações e abordagens da educação física, enxergaram a formação profissional e a consequente reforma curricular de 1992 na USP? Para entender melhor o que se passou nessa fase, foi realizada uma pesquisa de história oral com informantes que vivenciaram esse contexto.

\section{Métodos}

Com o objetivo de analisar os dados empíricos, adotou-se uma abordagem qualitativa através de uma pesquisa histórica, por meio do método de história oral apresentado por Paul Thompson (2002). Nesse método, os informantes são entrevistados pela técnica semiestruturada, na qual o entrevistador acessa a memória do informante a partir de um diálogo sobre determinado tema. Em nossa pesquisa, optamos por uma abordagem temática sobre os anos 1980 e sua repercussão no currículo da EEFE-USP.

Para Thompson (2002), a história oral fornece subsídios relevantes para levantamentos de dados que não se evidenciariam através da coleta de fontes escritas. $O$ ato de escrever é restrito a uma parcela da população que constituiria uma elite pensante. Desse modo, a vivência e a memória daqueles que estão excluídos da possibilidade da escrita se perdem no tempo. Assim, a história oral dá voz ao passado daqueles que não escrevem ou escreveram, mas vivenciaram o passado.

A tensão entre o escrito e o oral, o dominante e o dominado, constrói o cerne metodológico da história oral mais especificamente, pois a experiência do sujeito se coloca na relação entre a consciência coletiva e a experiência individual. Da mesma forma, não podemos conceber a ideia de que o Estado determina as mentalidades; ao contrário, é suscetível à influência da resistência dos indivíduos, em uma relação dialética (THOMPSON, 1997).

Em relação ao problema de pesquisa levantado, e a partir do pensamento de Edward Palmer Thompson (1997), nos interessa apontar a tensão entre a hegemonia do saber acadêmico da educação física na USP e aqueles professores ligados à prática esportiva vencidos no embate por uma reforma curricular.

O estudo contou com a colaboração de cinco informantes, respeitando os seguintes critérios de inclusão: a) professores concursados da EEFEUSP; b) professores que presenciaram a reunião da congregação que criou o curso de bacharel em esporte separado do bacharelado em educação física.

A análise dos dados obedeceu aos critérios de Paul Thompson (2002), a partir de uma sistematização da memória dos informantes através de uma transcrição. Posteriormente, foram levantados indícios de contradição com a revisão da literatura e entre os depoimentos orais dos informantes.

\section{Resultados e discussão}

Ao analisarmos os depoimentos dos informantes, levantamos a categoria de discussão do bacharelado. Para os informantes 1 e 4 , o contexto nacional caminhava para a organização do bacharelado. A constituição da pós-graduação em educação física no país, a titulação dos professores em cursos de doutorado no exterior, 
somadas à discussão sobre educação física escolar nos anos 1980 constituíram uma trama que possibilitou a reforma curricular de 1992 na EEFE-USP. Nos termos do informante 1, a necessidade da organização de um bacharelado pautava-se nos seguintes argumentos:

No Brasil o conceito de bacharelado na educação física brasileira [...], o conceito de bacharelado foi muito mal trabalhado e houve uma manipulação política, ideológica do conceito de bacharelado. Teve acadêmicos, pesquisadores até respeitados, influenciando a cabeça dos alunos de graduação, dizendo que o bacharelado se enquadrava em um modelo neoliberal, que o bacharelado era voltado para academias, que só atendia a elite brasileira, que o bacharelado era voltado apenas para pesquisadores, para elite, assim por diante. Pura miopia, as pessoas que falaram isso não têm o mínimo conhecimento do que seja o bacharelado [...]. Tentaram difamar o bacharelado, essa coisa toda, que esse grupo do barulho tenta trazer. Não conseguiram, ainda bem [...]. (Informante 1)

Este informante relata a trajetória desse processo fazendo uma crítica aos pesquisadores que se mostravam contrários à constituição do campo e à formação do bacharelado. No acesso à memória deste informante, as rupturas e discussões sobre a constituição do bacharelado não eram internas na EEFE-USP, mas sofriam pressões externas. Em seu depoimento, o informante 1 critica a falta de pluralidade no discurso acadêmico da educação física, colocando a EEFE-USP como lugar da diversidade de ideias:

Uma dessas abordagens (da educação física escolar) tentou ser hegemônica, isso é um crime intelectual. Uma das abordagens começou a falar: essa abordagem não presta, esta não presta, esta não presta, vocês já sabem qual é essa abordagem, e deu no que deu. [...] Essa escola (EEFE-USP) foi, evidentemente, plural sempre. Assim como a USP é. Aqui nós fazemos congresso de educação física escolar e convidamos a todos, todos eles, desde o começo. O primeiro congresso nosso, [...] nós convidamos Celi, Lino, João Batista esteve aqui várias vezes. Válter Bracht esteve aqui várias vezes, Mauro Betti, Kunz várias vezes, esse pessoal todo, sempre foram convidados para nossos eventos, para nossas bancas. Agora, nossos alunos de graduação nunca foram suscetíveis a este tipo de... de... de iniciativa, não me pergunte 0 porquê. Talvez porque não teve muito espaço. Agora tem um pouco de espaço, alguns professores tentam agitar alguma coisa, mas nós acomodamos isso numa boa. Querem se reunir, se reúnam. Agora mesmo tem o pessoal do diretório nacional do não sei das quantas, ok. A universidade deve ser assim [...]. (Informante 1)
O informante 4 também observa que 0 processo de discussão da década de 1980 culminou na reforma curricular de 1992, em um contexto de mudanças e novas discussões da área. No depoimento do informante 4:

Neste processo aí, aqui na escola... Agora, uma discussão que foi colocada: a educação física tinha que ter um objeto de estudo, era uma ciência que tinha que ter um objeto de estudo. Aí se falou, assim, o objeto da educação física é o movimento humano, mas movimento humano é muito amplo, atividade motora, atividade física, é muito amplo. Aí alguém veio e disse: nosso objeto também é o esporte. $E$ aí você vai encontrar na literatura muita gente escrevendo sobre esporte do ponto de vista filosófico, sociológico, psicológico. Muita gente escrevendo sobre o esporte como fenômeno marcante no século 20, fenômeno sociocultural. Tudo isso fez com que houvesse uma percepção de que seria interessante diferenciar o fenômeno com que trata a educação física... Alguns vão dizer que a educação física na escola, de algo relacionado ao ensino da educação física na escola, outros vão dizer que é o exercício, e tudo isso é diferente do esporte, enquanto instituição, enquanto algo regrado por federações, confederações, associações. Isso gera a necessidade de você ter um profissional que entenda disso em particular [...]. Até hoje, aqui, as pessoas não têm clara essa diferenciação, as pessoas não conseguem distinguir o esporte como fenômeno e o esporte como instituição. O bacharel em esporte lida com o esporte como instituição, é aquele indivíduo que vai trabalhar no clube esportivo, na federação [...]. Já o profissional de educação física lida com o fenômeno esporte, mas ele não vai nesse campo da instituição, ele lida com o esporte como algo que ele pode usar para o processo de educação, seja na escola ou fora da escola. Eu posso trabalhar com o esporte sendo professor de educação física, só que meu objetivo não é formar uma equipe esportiva, não é formar um atleta, é colocar o esporte a serviço da educação física. Bacharel em esporte não está preocupado com inclusão, quero selecionar 0 talento esportivo [...]. (Informante 4)

Podemos perceber 0 deslocamento da discussão do informante 4 para outra perspectiva, pois, diferentemente do informante 1 , ele caminha para a divisão do bacharelado em esporte e educação física. Ou seja, embora concorde com o informante 1 sobre a questão da necessidade de formação do bacharelado, ressalta as rupturas internas existentes na própria EEFE-USP. Sobre a divisão entre educação física e esporte, responde da seguinte forma:

Traumática, traumática, porque... toda vez que você vai fazer uma mudança muito grande, o aspecto conceitual dela, que já é complicado, nem sempre tá em primeiro plano, o que está em primeiro plano é a questão de poder, né? As 
pessoas sempre pensam assim: o que vou ganhar, o que vou perder. E quem estava no poder na época não conseguia ver essa distinção claramente, embora muita gente que estava no poder na época... eram pessoas do esporte como instituição, diretores, vicediretores, que eram, tinham sido técnicos de seleção brasileira, que tinham atuado no esporte, eles não conseguiam ver essa distinção. Até porque havia essa confusão. Então houve esse embate político [...]. A ponto de ficar dois grupos, um grupo de manutenção, e um grupo mais jovem que defendia a distinção. [...] foi na congregação que votou-se, aí a votação foi 9 a 8, se não me engano, uma coisa assim, então por um voto venceu a divisão entre educação física e esporte. [...] por trás dessa mudança estava o quê? Estava a pós-graduação, estava a constituição de uma área de conhecimento, estava a necessidade dos professores fazerem pesquisa, [...] durante um bom tempo houve rusgas sobre isso. Eu fiz uma prova de natação que eu tinha que ficar uma hora e meia na parte funda da piscina sem tocar em nada, como um náufrago. [...] foi a partir de 88, 91 que isso mudou. (Informante 4)

Nesse depoimento revela-se uma ruptura na EEFE-USP que não foi apresentada pela literatura, nem pela memória do informante 1.0 informante 4 relata uma divisão traumática entre a velha e a nova geração de professores da EEFEUSP. Ou seja, aqueles mais antigos eram ligados ao esporte, e os novos, predominantemente ligados à pesquisa, eram aqueles oriundos de cursos de pós-graduação. Essas divergências que se desenharam na década de 1980 tiveram seu ápice na reforma curricular de 1992. Essa reforma criou a divisão entre bacharelado em esporte e educação física e foi votada na congregação da EEFE-USP. Os informantes 2 e 3 confirmam o mesmo evento: "Ela foi traumática, ela não foi consensual... Foi uma votação de $9 \mathrm{a}$ 8" (Informante 3). "...É, pra vocês terem uma ideia, foi uma votação de 9 a 8" (Informante 2). 0 informante 3 descreve 0 contexto dessa discussão em detalhes:

...com muito maniqueísmo, quem era contra era radicalmente contra, quem era a favor era visceralmente a favor, havia trincheiras... Eles não reconhecem 0 potencial educativo das atividades esportivas, eles acham que esporte não educa ninguém, o esporte... O clima, clima emocional, o clima emocional que se instalou na votação do 9 a 8 , no 9 a 8 que se estende até hoje, então tudo o que o pessoal do esporte faz pra tentar fazer uma coisa melhor o outro grupo vê como boicote ao projeto da escola, tão boicotado o projeto da escola... Às vezes a gente quer fazer uma coisa legal que acha certo, tudo bem já passou, já faz muitos anos, mas tem gente que fica mordido com essa coisa emocional, isso permanece até hoje. Isso é péssimo, há professores aqui que não se falam. Há professores que poderiam ser convidados para dar aula um no curso do outro, e nós temos professores do esporte que poderiam dar aula belíssima no curso de educação física, nem convida, nem convida. $\mathrm{E}$ no curso, em contrapartida, também no curso de esporte, aí então no curso de esporte nós vamos fazer a disciplina. Poderíamos convidar gente que dá aula no curso de educação física para dar a sua contribuição, seria razoável no ambiente acadêmico universitário, no mínimo razoável, eles não convidam. (Informante 3)

Percebemos que a pluralidade da EEFE-USP, defendida pelo informante 1 , é colocada em discussão pelo informante 3 . Os depoimentos revelam divergências profundas entre os grupos na EEFE-USP quando o assunto é a reforma curricular de 1992. Os informantes 2 e 5 relatam o seguinte:

É, foi até meio passional. Nós somos da linha que o esporte é uma ferramenta da educação física, e você utiliza o esporte pra fazer com que a educação física seja mais concreta, se motive, tenha, digamos, ah, um aspecto, ah, não só lúdico, mas também competitivo, participativo, integrativo. E é difícil você ter esses elementos sem ter o esporte, e vai ficar só o quê? Jogando, brincando, fazendo exercício? Então o esporte sempre foi, e a divisão justamente foi essa. Houve uma ruptura tão forte... (Informante 2)

Até 1992, tínhamos o curso de licenciatura. A partir de 92, a USP mudou para bacharel, quatro anos. Mas o bacharel em educação física, o bacharel em esporte... O que era apenas para ser uma divisão acadêmica virou divisão, divisão mesmo, a ponto de estudantes de educação física não conversarem com estudantes de esporte, e professores que foram para o Departamento de Esporte não conversarem com professores da educação física. Quer dizer, em um primeiro momento é um absurdo o que aconteceu lá. (Informante 5)

A partir dos depoimentos dos informantes 2, 3, 4 e 5 , percebemos que a diversidade presente na discussão acadêmica, a questão da pluralidade, a aceitação das diferenças entre as ideias propostas não foram objeto de um debate científico que poderia produzir inovações. $\mathrm{Na}$ verdade, a questão do bacharelado parece ter sido vivenciada muito mais de forma passional, carregada de emoções, que se mostraram afloradas no acesso à memória dos informantes.

Embora o informante 1 tenha mencionado o contexto da década de 1980 a partir de um debate ocorrido com todos os pesquisadores contrários às ideias da EEFE-USP, os outros informantes limitaram o debate apenas ao contexto interno da EEFE-USP, algo também não revelado pela literatura. 


\section{Considerações finais}

Segundo nossa pesquisa, é possível perceber que o contexto de debate dos anos 1980 na educação física brasileira influenciou a reforma curricular de 1992. Destacam-se os debates sobre o objeto de estudo da área e o perfil de formação do profissional desejado.

Em relação ao objeto de estudo, seus debates serviram para questionar o esporte, tido para alguns como sinônimo de educação física, fato que gerou a necessidade de reformulação de currículos, inclusive da EEFE-USP. Esta instituição, entendendo o esporte e a educação física como fenômenos diferenciados, e levando em consideração o perfil do egresso, optou pela criação de um bacharelado em educação física e um bacharelado em esporte. A licenciatura tornou-se um complemento da formação no currículo da Universidade de São Paulo, já que, segundo os informantes, interessava a uma minoria de alunos.

A partir dos argumentos de uma formação profissional coerente com o perfil do egresso, a EEFE-USP colocou-se como modelo de formação em contraponto com outras instituições paulistas e de outros estados. Essas divergências se mostraram acirradas nos debates em torno da educação física escolar e nas diversas abordagens que se organizaram nos anos 1980 e 1990.

No entanto, um fator original revelado neste estudo foi a existência de divergências internas, as quais, após análise interpretativa, são percebidas como ainda presentes na EEFE-USP. Os informantes representaram grupos com visões diferentes sobre a educação física e o papel do esporte na área, deflagradas como conflituosas. Conflitos que, segundo os informantes, geram questionamentos até 0 cenário atual. Fica evidente que um grupo formado não desejava a separação entre educação física e esporte, contudo não se organizaram academicamente para este debate.

\section{Referências}

BARROS, J. M. C. Educação Física na UNESP de Rio Claro: bacharelado e licenciatura. Motriz.

Revista de Educação Física. UNESP, Rio Claro, v.1, n.1, p.71-80, 1995.

BARROS, J. M. C. Educação Física: perspectivas e tendências na profissão. Motriz. Revista de Educação Física. UNESP, Rio Claro, v.2, n.1, p. 49-52, 1996.
BETTI, I. C. R.; BETTI, M. Novas perspectivas na formação profissional em Educação Física.

Motriz. Revista de Educação Física. UNESP, Rio Claro, v.2, n.1, p.10-19, 1996.

CARMO, A. A. Educação Física: uma desordem para manter a ordem. In: OLIVEIRA, V. M. (Org.) Fundamentos pedagógicos da Educação Física. Rio de Janeiro: Ao Livro Técnico, 1987, p.41-47. (Coleção Fundamentos Pedagógicos 2).

DAÓLIO, J. Educação Física: autores e atores da década de 1980. Campinas: Papirus, 1998.

DAÓLIO, J. Educação Física e conceito de cultura. Campinas: Autores Associados, 2005.

DARIDO, S. C.; RANGEL. I. C. A. Educação Física na escola: implicações para prática pedagógica. Rio de Janeiro: Editora Guanabara Koogan, 2005.

FREIRE, E. S.; VERENGUER, R. C. G.; REIS, M. C. C. Educação Física: pensando a profissão e a preparação profissional. Revista Mackenzie de Educação Física e Esporte, São Paulo, v.1, n.1, p.39-46, 2002.

GALVÃO, Z. Educação Física Escolar: a prática do bom professor. Revista Mackenzie de Educação Física e Esporte, São Paulo, v.1, n.1, p.65-71, 2002.

KOLYNIAK FILHO, C. Educação Física: uma introdução. São Paulo: Pontifícia Universidade Católica, 1998.

KUNZ, E. A imprescindível necessidade pedagógica do professor: o método de ensino. Revista Motrivivência, Florianópolis, v.11, n.13, p.63-80, 1999.

MAGALHÃES, C. H. F. Breve histórico da Educação Física e suas tendências atuais a partir das identificações de algumas tendências de idéias e idéias de tendências. Revista da Educação Física/UEM, Maringá, v.16, n.1, p.91102, 2005.

MANOEL, E. J.; TANI, G. Preparação profissional em Educação Física e Esporte: passado, presente e desafios para o futuro. Revista Paulista de Educação Física, São Paulo, v.13, n. especial, p.13-19, 1999.

NISTA-PICCOLO, V. L. Prolegômenos de uma pesquisa sobre o perfil do professor de Educação Física. Revista Brasileira de Docência, Ensino e Pesquisa em Educação Física, Cristalina, v.2, n.1, p.111-125, 2010.

OLIVEIRA, A. A. P.; DA COSTA, L. P. Educação Física/esporte e formação profissional/campo de 
trabalho. In: GOELLNER, S. V. (Org.). Educação Física/ciências do esporte: intervenção e conhecimento. Florianópolis: Colégio Brasileiro de Ciências do Esporte, 1999, p.83-99.

OLIVEIRA, A. A. B. Mercado de trabalho em Educação Física e formação profissional: breves reflexões. Revista Brasileira de Ciência e Movimento, Brasília, v.8, n.4, p.45-50, 2000.

OLIVEIRA, V. M. Consenso e conflito da Educação Física brasileira. Campinas: Papirus, 1994.

PÉREZ GALLARDO, J. S. Educação Física: contribuições à formação do profissional. ljuí: Ed. Unijuí, 1997.

\section{SILVA NETO, A. M. As reformas do ensino da} Educação Física na Universidade de São Paulo (1970-1992): um diálogo entre gerações. 2002. 152 f. Dissertação (Mestrado em Educação) - Universidade Presbiteriana Mackenzie, São Paulo, 2002.

SILVA, R. N.; ESPOSITO, Y. L.; SAMPAIO, M. M.; QUINTEIRO, J. Formação de professores no Brasil: um estudo analítico. São Paulo: Fundação Carlos Chagas/ REDUC, 1991.

SILVEIRA, S. R.; TANI, G. Educação Física como área de conhecimento na Escola de Educação Física e Esporte da USP: um estudo da sua trajetória e constituição a partir do seu periódico institucional. Revista Brasileira de Educação Física e Esporte, São Paulo, v.22, n.1, p.35-44, 2008.

SOARES, C. L. Educação Física Escolar: conhecimento e especificidade. Revista Paulista de Educação Física, São Paulo, supl.2, p.6-12, 1996.

TAFFAREL, C. N. Z. A formação profissional e as diretrizes curriculares do Programa Nacional de Graduação: 0 assalto às consciências e 0 amoldamento subjetivo. Revista da Educação Física/UEM, Maringá, v.9, n.1, p.13-23, 1998.

TANI, G. Educação Física: por uma política de publicação visando a qualidade dos periódicos. Revista Brasileira de Ciências do Esporte, Campinas, v.29, n.1, p.9-22, 2007.

TANI, G. Abordagem desenvolvimentista: 20 anos depois. Revista da Educação Física/UEM, Maringá, v.19, n.3, p.313-331, 2008.

TANI, G.; MANOEL, E. J.; KOKOBUN, E.; PROENÇA, J. E. Educação Física Escolar: fundamentos de uma abordagem desenvolvimentista. São Paulo: EPU, 1988.
THOMPSON, E. P. Senhores e caçadores. Rio de Janeiro: Paz e Terra, 1997.

THOMPSON, P. A voz do passado. 5.ed. Rio de Janeiro: Paz e Terra, 2002.

TOJAL, J. B. A. G. Currículo de graduação em Educação Física: a busca de um modelo. Campinas: Editora da UNICAMP, 1989.

TOJAL, J. B. A. G. Motricidade humana: o paradigma emergente. Campinas: Editora da UNICAMP, 1994.

VERENGUER, R. C. G. Preparação profissional em Educação Física: das leis à implementação de currículos. 1996. 95 f. Dissertação (Mestrado em Educação) - Faculdade de Educação Física, Universidade Estadual de Campinas, Campinas, 1996.

VIANNA, J. A.; LOVISOLO, H. R. Desvalorização da aprendizagem técnica na Educação Física: evidências e críticas. Motriz. Revista de Educação Física. UNESP, Rio Claro, v.15, n.4, p.883-889, 2009.

Endereço:

Edivaldo Góis Junior

Avenida Pasteur, 250 Fundos, $2^{\circ}$ andar,

Faculdade de Educação, Departamento de Didática

Praia Vermelha - Rio de Janeiro - RJ Brasil 22290-240

e-mail: egoisjunior@gmail.com

Recebido em: 4 de outubro de 2010. Aceito em: 11 de abril de 2012. 